\title{
Histórias Interativas para a Disciplina de História no Ensino Médio: Uma Abordagem de Autoria Compartilhada
}

\author{
Marcelo Peixoto Marques - celohistoria@gmail.com - PPGTER/UFSM \\ Andre Zanki Cordenonsi - andrezc@ inf.ufsm.br - PPGTER/UFSM
}

\begin{abstract}
Resumo: O presente estudo apresenta uma proposta de utilização de novas tecnologias educacionais como alternativa capaz de contribuir positivamente no processo de ensino de História. Assim sendo, buscou-se analisar a produção de um jogo de histórias interativas, por meio da utilização dos softwares Twine e Storybird em uma escola pública de ensino médio, no município de Restinga Sêca. Este estudo teve caráter qualitativo, nesse sentido utilizou-se como metodologia o estudo de caso, visando analisar o comportamento de alunos e professores e o direcionamento do processo de ensino e aprendizagem mediado pelas tecnologias. Ficou evidenciado nessa pesquisa o fomento de novas possibilidades de interação no cenário educacional, por meio de uma abordagem capaz de aproximar os conteúdos programáticos da disciplina de História, com novas ferramentas tecnológicas capazes de ressignificar a relação da disciplina com os alunos.
\end{abstract}

Palavras-chave: Histórias Interativas, Ensino de História, Jogos Educacionais

\section{Interactive Stories History for History Teaching in High School: A Shared Authorship Approach}

Abstract: The present paper presents a proposal to use new educational technologies as an alternative capable of contributing positively to the History teaching. The paper analyzes the production of interactive stories games using Twine and Storybird software in a public high school in the Restinga Sêca city. It was a qualitative approach by the use of a case study methodology, aiming to analyze the behavior of students and teachers in the process of teaching and learning mediated by technologies. It was evidenced in this research the promotion of new possibilities of interaction in the educational scenario, through an approach capable of approaching the programmatic contents of the History course, with new technological tools able to create new meanings in the relation of the discipline with the students.

Keywords: Interactive Stories, History Teaching, Educational Games

\section{Introdução}

A prática do ensino de História remete os alunos, muitas vezes, a recuos imaginários absurdamente remotos no tempo, ao passo que as tecnologias apresentam-lhes um presente contínuo. Portanto, repensar as aulas e as estratégias de ensino é uma tarefa urgente. Acredita-se que os recursos das tecnologias educacionais possam agregar ao ensino de História, a produção de ferramentas motivadoras e decisivas na aprendizagem escolar, destacando a necessidade de uma modificação nos currículos escolares, no que diz respeito à exploração das TICs como ferramentas pedagógicas.

De maneira a contribuir com essa realidade, este trabalho tem o objetivo geral de

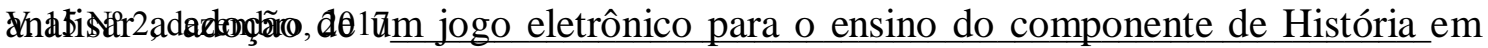
uma escola pública de ensino médio, no município de Restinga Sêca-RS. Para tanto, 
destacam-se os seguintes objetivos específicos: fazer um diagnóstico das metodologias de ensino de história que abordem a tecnologia como ferramenta mediadora do processo de ensino e aprendizagem e analisar por meio dos softwares Twine e Storybird, o processo de ensino e aprendizagem, de duas revoltas sociais ocorridas na Primeira República em uma escola pública de ensino médio em Restinga Sêca-RS. Ressalta-se que os conteúdos históricos escolhidos fazem parte do programa do componente da disciplina de História, no terceiro ano do ensino médio e, além disso, buscam valorizar momentos decisivos da História do Brasil, fomentando a valorização de acontecimentos e personagens que apresentaram sua indignação e revolta frente ao poderio das elites locais.

\section{O Uso de Novas Metodologias no Ensino de História}

O cenário educacional contemporâneo é tema de muitos debates e estudos que almejam maior qualidade para práticas formativas, capazes de apresentar caminhos que legitimem uma relação harmoniosa entre os novos adventos tecnológicos e as ações da humanidade, em um cenário globalizado e estruturado em plurais e complexas redes de interação. Para França e Simon (2005), sobre as possibilidades de utilização das tecnologias no ensino de História, tem-se a seguinte posição: "em relação às dificuldades apresentadas às mudanças encontradas na sociedade e a manutenção da posição conservadora da escola em pleno século XXI, ainda tem-se a esperança da possibilidade de inovação na prática docente e o rompimento com a concepção tradicional de ensino".

Romper com abordagens factuais que privilegiam apenas o uso de textos, e questionários com perguntas e respostas, é um desafio a alguns professores de História. É preciso buscar ferramentas que minimizem a abordagem que limita a apenas a contar a História de grandes guerras, vencedores, datas e fatos importantes em organização cronológica, sem articulação com as histórias das pessoas, do bairro, da cidade, enfim, do mundo. Dentro da ótica de Moura (2009), o ensino de história ainda se encontra de maneira factual e a estrutura universitária precisa mudar gradativamente para que o ensino de história instigue alunos e professores a práticas de pesquisas que venham a beneficiar o ensino fundamental e médio e, consequentemente, direcionando novas formas metodológicas para o ensino de história. A produção universitária sobre o tema ainda é restrita se comparada à produção de outros temas ligados à história e/ou historiografia, refletindo em dificuldades para desenvolver estudos a respeito do assunto. As novas ideias e o uso de recursos tecnológicos que fazem parte do cotidiano contemporâneo dos alunos são ingredientes que oportunizam abordagens interativas para o ensino de História, tornando a disciplina atrativa, criativa e empolgante.

\section{Tecnologias: o Twine e o StoryBird}

Nas últimas décadas, os debates e publicações sobre o uso de jogos eletrônicos na educação formal está se tornando cada vez mais premente (Maklund, Alkind, 2016). No entanto, alguns ainda consideram os jogos como algo de natureza difícil e exótica por muitos professores, seja pelos problemas envolvidos na observação dos resultados ou pela complexidade que envolve os processos de avaliação nessa área (EgenfeldtNielsen, 2010). $\mathrm{Na}$ intenção de reunir mobilidade e interatividade ao programa curricular da disciplina de História no terceiro ano do ensino médio, foram escolhidos os softwares Twine e Storybird. O Twine é antes de qualquer coisa um aplicativo para se contar histórias interativas. Não requer conhecimento muito aprofundado de técnicas interativas, física ou modelagem, mas permite a produção de um jogo de histórias interativas num formato digital, A inspiração para o desenvolvimento dessa ferramenta

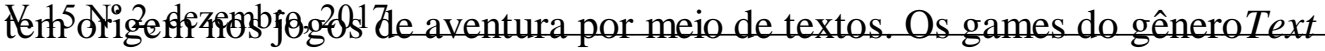


Adventures veiculam a história do jogo, por meio da apresentação de textos revelados ao jogador, na medida em que ele vai manifestando suas decisões diante do ambiente e circunstâncias em que se encontra. Durante a execução do jogo, o usuário participa, assumindo o papel de uma personagem, de uma história construída com base em suas decisões e na lógica predefinida pelo programa. (Oliveira, 2009).

Para tanto, é necessário refletir que a escolha do ambiente de programação deve ir ao encontro da realidade das configurações das máquinas disponíveis no laboratório de informática da escola. Pensando essa necessidade, o Twine possui características que não se configuram como empecilho para a otimização das ações, já que tem código aberto e, é gratuito, além de permitir uma fácil instalação. Uma ferramenta como Twine pode ser especialmente útil para apresentar escolhas que confrontam os indivíduos em circunstâncias difíceis, por exemplo, como criar um orçamento com recursos limitados ou fazer uma viagem perigosa em todos os continentes. Os leitores podem ganhar uma nova perspectiva em primeira mão a partir das matérias que leem. A produção textual é a principal característica do Twine, o que há de inovador é a possibilidade do aluno se perceber como autor da História, e nela agregar informações atualizadas e novos entendimentos sobre o recorte histórico abordado. A figura 1(a) mostra que o modo de edição direciona para diversas passagens que são nomeadas de acordo com a criatividade dos alunos e os desafios que podem ser lançados nas mesmas. A posição das passagens e desafios resulta em múltiplos designes de acordo com o processo de criação do aluno. Dessa maneira, o diagrama em alguns momentos lembra um mapa conceitual.

Figura 1: Twine e StoryBird
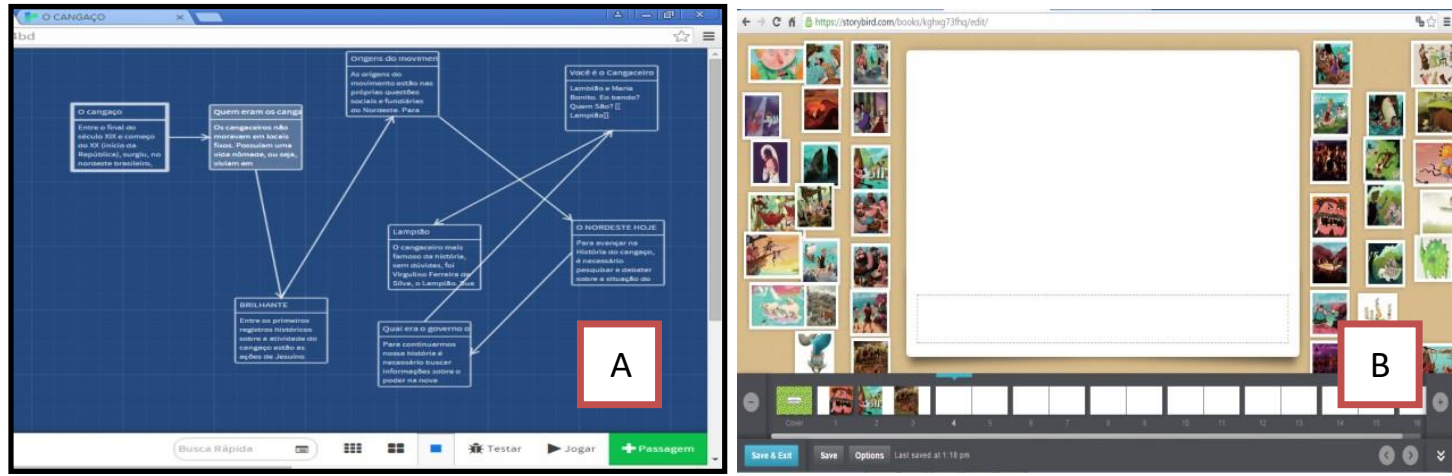

A ferramenta Storybird possibilita a construção de histórias interativas na forma de livro digital, com a possibilidade de criar histórias através da seleção de ilustrações de diversos artistas, associando-se a estas ilustrações aos conteúdos programáticos previamente elencados. As funcionalidades da ferramenta também possibilitam o compartilhamento das histórias, a consulta e troca de comentários sobre as mesmas. A figura 1(b) ilustra a tela inicial que direciona para o início do processo criativo. $\mathrm{O}$ software Storybird permite ao aluno produzir textos integrando o conhecimento assimilado nas aulas. Além de possibilitar a ilustração e criação de novos cenários, estimulam a criatividade e a imaginação, requisitos importantes no mundo atual. Os usuários podem escrever suas próprias histórias, ler as histórias dos outros autores, e seguir as publicações de outros autores. Para criar um novo texto, o autor deve selecionar uma ilustração para cada página, a partir de uma galeria de ilustrações. 


\section{Metodologia}

A pesquisa foi realizada na Escola Estadual de Ensino Médio Érico Veríssimo de Restinga Sêca (RS, Brasil). A escola possui laboratório com 18 computadores com internet de banda larga. Foi escolhida a turma trezentos e três, do terceiro ano do ensino médio, composta por vinte e seis estudantes (12 do sexo masculino e 14 do sexo feminino), com idade entre 16 e 17 anos, quase que em sua totalidade formada por alunos oriundos de localidades rurais. Ressalta-se que o perfil da turma agrega características subjetivas que resultam em alunos comprometidos, questionadores, afetuosos e participativos, possibilitando ao educador o direcionamento da proposta e atuação de forma a contribuir com a discussão de uma nova metodologia para o ensino de História.

Buscando aproximar o ensino de História com a necessidade de uso das TICs no cenário educacional, foi proposto a discussão de duas revoltas ocorridas na primeira república, Canudos e Cangaço, por meio do uso das ferramentas Twine e Storybird. Inicialmente os temas propostos foram apresentados em formato de textos, documentários, filmes e atividades de pesquisa no Labin da escola. Durante as atividades, o professor buscou e discutiu as temáticas históricas com os alunos, procurando, por meio de exposições dialogadas e leitura de imagens e vídeos, explicar melhor qual relação seria possível estabelecer para a produção do jogo com histórias interativas. Percebe-se que a necessidade de fomentar novas metodologias para o ensino de história, vem sendo discutidas desde a publicação do Guia Metodológico para cadernos MEC - História, em 1971, que pretendiam incentivar novas práticas pedagógicas na escola, com o estabelecimento de dispositivos, os novos procedimentos de ensino para o professor e as atividades didáticas de aprendizagem para os alunos.

Os alunos trabalharam em grupos de quatro e cinco alunos, de modo a facilitar a orientação do professor e posterior socialização de resultados com toda turma. Salientase que a proposição de pesquisa contemplou o programa do componente de História do terceiro ano do ensino médio e a divisão dos alunos por temática deu-se por sorteio. Os dados e intervenções relativas à pesquisa buscaram verificar de que maneira a aplicação de jogos educacionais pode tornar mais atrativo o ensino de história. Para aprendizagem das ferramentas e produção das histórias interativas foi necessário a utilização de três horas aulas semanais no período de seis meses. Cabe salientar que as ações que foram realizadas, foram aprovadas pelo comitê de ética e pesquisa da Escola Estadual de Ensino Médio Érico Veríssimo. Ressalta-se que os alunos envolvidos, ao final do estudo, responderam um questionário apontando suas percepções sobre a participação nesse estudo e qual a realidade da escola com o uso das tecnologias antes de sua participação. O objetivo dessa ação, além de criar um diagnóstico concernente às relações estabelecidas com tecnologias educacionais na escola e verificar os impactos percebidos no decorrer desse estudo, tem possibilidades de configurar-se como uma ferramenta norteadora para os futuros planejamentos de ações da Escola Estadual de Ensino Médio Érico Veríssimo.

\section{A Produção de Histórias Interativas}

A proposição de criação de jogos com histórias interativas, ligando fatos históricos à utilização de ferramentas tecnológicas, em acordo com Silveira (2012), propicia uma nova abordagem sobre o ensino de História - desapegada da História tradicional que privilegia os grandes acontecimentos de personagens heróicos e datas marcantes revelam que os conteúdos históricos alinhados com adventos da atualidade, podem facilitar a compreensão do aluno, possibilitando-o sentir-se como agente dessa História. V. $15 \mathrm{~N}^{\circ}$ 2, dezembro, 2017

A nova tendência privilegia uma "História viva", ou seja, uma História que desperte no 
aluno a curiosidade para conhecer a sua vida, a realidade que o rodeia, em nosso caso, especificamente, a realidade ligada à necessidade de incorporação das tecnologias no contexto dos estudos. No entendimento dessa perspectiva o Labin da Escola Estadual de Ensino Médio Érico Veríssimo de Restinga Sêca, configurou-se como um espaço totalmente aberto à criação, resolução de dúvidas e constante troca de ideias. Divididos em grupos e por temáticas históricas, os alunos produziram dois jogos, com histórias interativas contemplando situações de construção de aprendizagens dos períodos históricos de Cangaço (utilizando a ferramenta Twine), como pode ser visualizado na figura 2(a) e Guerra de Canudos (utilizando a ferramenta Storybird) como pode ser visualizado na figura 2(b). A introdução textual de ambas partiu da afirmação "Os acontecimentos de Canudos e o Cangaço continuam a repetir-se a cada instante na sociedade contemporânea...". Partindo dessa premissa, os alunos criaram produções que instigavam os demais a conhecer o contexto histórico ocorrido no início do século XX, e, perceber que no cenário atual, no campo e nas grandes cidades, pequenas elites econômicas e políticas colocam parte da sociedade brasileira em conflito.

Figura 2: Histórias Interativas Produzidas

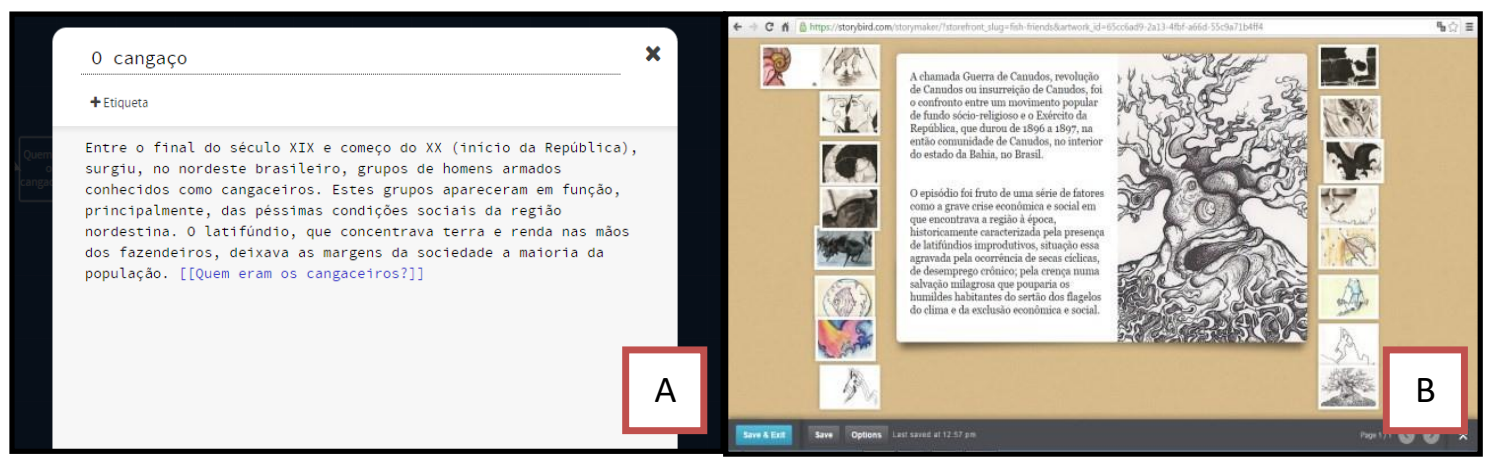

\subsection{História interativa "O Cançaco"}

Partindo do fomento dessa percepção sobre a realidade contemporânea brasileira a produção do jogo com histórias interativas confirmou o protagonismo dos alunos nas muitas situações, em que os mesmos foram provocados a propor soluções para a resolução das problemáticas contemporâneas. Uma discussão importante para esse estudo, diz respeito à ligação feita pelos alunos, entre os cangaceiros e as milícias espalhadas por todo país. Nesse momento da produção, foi formado um debate caloroso, sobre diversas problemáticas sociais que se evidenciam no país. Nesse sentido, é importante destacar que em anos anteriores, quando essa mesma temática era debatida, a participação dos alunos não foi tão calorosa e a troca de ideias não atingia toda turma.

Nesse caso, evidenciou-se por meio da colaboração textual, mediada pela utilização da ferramenta Twine, a participação e argumentação efetiva e de qualidade de todos os alunos da turma. Essa evidência contribui para a confirmação das potencialidades do uso das TICs, para o direcionamento de uma prática pedagógica capaz atrativa para os alunos. A estruturação do jogo com história interativa sobre o Cangaço contemplou inicialmente uma sucinta apresentação sobre o conteúdo, visto que o embasamento teórico mais aprofundado foi discutido anteriormente e se faz presente no livro didático da disciplina de História. Em seguida, foram escolhidos e apresentados os personagens. Sendo assim, as produções feitas pela turma trouxeram em seus enredos denúncias de profundas desigualdades socioeconômicas, geradas pela falta de oportunidades, pelo descaso do poder público e pelo preconceito.

Mesmo sendo um software de linguagens simples, inicialmente alguns alunos tiveram dificuldades para se apropriar dos conhecimentos básicos de programação do Twine, evidenciando que muitos recebem o título de multitarefa, mas efetivamente, em alguns casos 19 poucos désembro, 201 uttilizar as ferramentas tecnológicas além das redes sociais, uma vez 
que a escola ainda não consegue possibilitar o acesso e permanência ao uso das TICs, na prática docente. Essa constatação oferece argumentos para pensarmos que nem todo jovem da chamada geração "Z" está conseguindo acompanhar o avanço das novas tecnologias. Ao pensarmos que o fenômeno da globalização que torna a circulação da informação de maneira instantânea, acontece de forma desigual em alguns pontos do planeta, temos elementos para justificar essa questão e apontar resoluções. A partir do engajamento dos alunos a cada semana que se passava, foi possível perceber o despertar de novas habilidades para o uso das tecnologias, pois os mesmos gradativamente foram se apropriando das lógicas de programação do Twine e, em muitos casos, solicitando desafios mais complexos.

\subsection{História interativa "Guerra de Canudos"}

Os alunos que foram direcionados para a produção do jogo de histórias interativas mediadas pela ferramenta Storybird tiveram um desafio um pouco mais complexo, em virtude de que, ao contrário do aplicativo Twine, o Storybird não permitia a escolha das imagens ilustrativas para as criações. O software possui uma infinidade de imagens e a partir delas os enredos devem ser ilustrados. No primeiro contato com o Storybird, os alunos apontaram dificuldades para aproximar o contexto da Guerra de Canudos com as primeiras impressões que tiveram das imagens disponíveis na ferramenta. Inicialmente se pensou na escolha de outro software para ser testado, mas uma aluna contribuiu com a resolução da problemática, ao sugerir o apoio da professora de Artes, para o entendimento e leitura de imagens que pudessem estabelecer uma comunicação, histórica e artística com o conteúdo analisado. A professora de Artes participou de três encontros, e neles promoveu discussões que aguçaram a interpretação e leitura de imagens, partindo da percepção de elementos que remontam ao espaço geográfico, personagens e momentos importantes da Guerra de Canudos. Ressalta-se nesse momento da pesquisa, a importância da interdisciplinaridade para a efetivação de processos de ensino e aprendizagens integrados. Sabemos que a História e a Arte estão interligadas pela expressão do homem em seus registros pré-históricos. Por isso, podemos trabalhar a interdisciplinaridade dessas áreas do conhecimento através de projetos, com vistas à abordagem de conteúdos e contextualização destes.

Buscando melhor explicar essa questão, o ver e o visualizar permitem ao leitor o entendimento dessa complexidade e das subjetividades dos alunos na escolha de algumas ilustrações presentes na história interativa, produzida com a ferramenta Storybird a partir da figura 3. Percebe-se neste espaço da pesquisa, que a utilização do Storybird levantou o surgimento de situações que permitiram o desenvolvimento de habilidades indispensáveis para que o indivíduo possa ser "inserido na realidade, para compreendê-la e, também, para alterá-la, como ferramentas do entendimento" (Scholze, Rösing, 2007). Portanto, perceberam-se na prática as possibilidades de atuação de maneira interdisciplinar, pois sutilmente, sem planejamento prévio forem edificadas ações entre as disciplinas de História e Artes. Nessa perspectiva, Fazenda (2011) aponta que projeto interdisciplinar não se ensina, nem se aprende: vive-se, exerce-se. A responsabilidade individual é a marca do projeto interdisciplinar. 
Figura 3: Representações Imagéticas Escolhidas pelos alunos

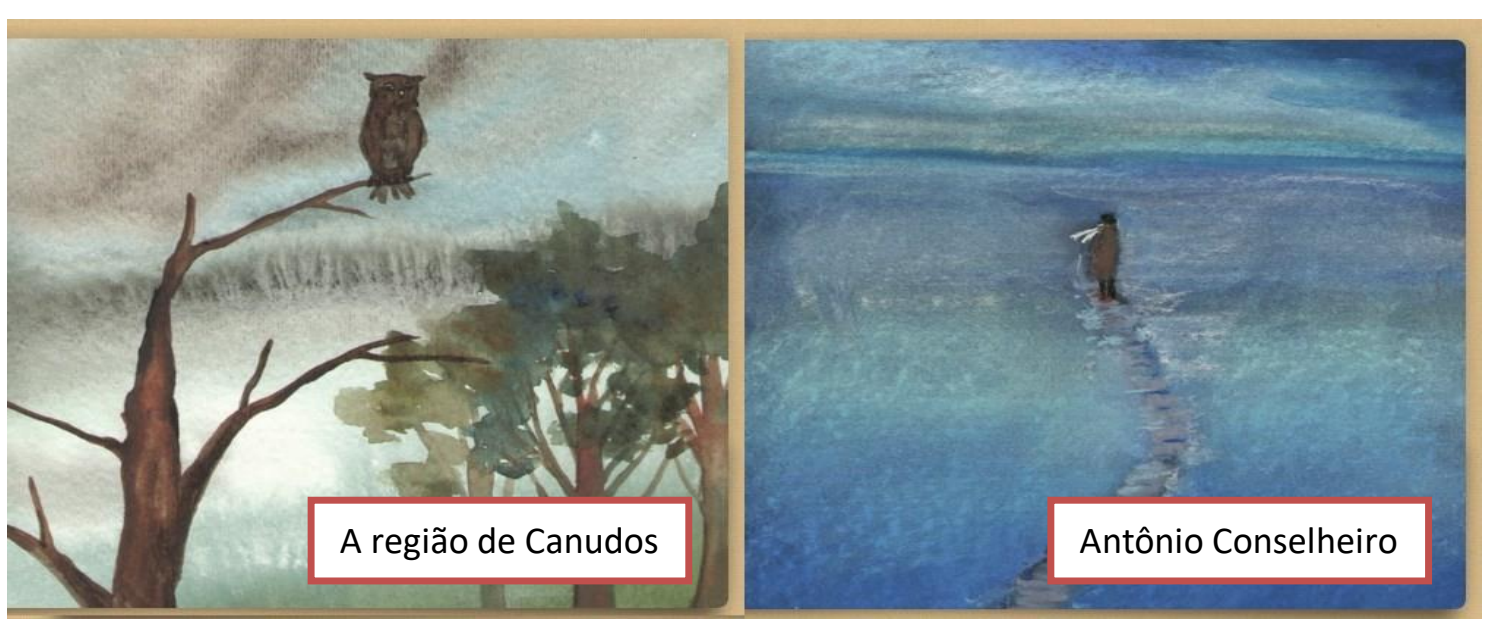

\section{Resultados e Discussões}

Com o propósito de verificar as percepções dos alunos durante a execução desse estudo e conhecer qual a sua relação com o uso das tecnologias na Escola Estadual de Ensino Médio Érico Veríssimo, fez-se necessário aplicar dois questionários com os alunos, na intenção de mostrar um diagnóstico e discutir os impactos evidenciados durante o processo de ensino e aprendizagem mediado pelo uso TICs. Para atingir esse propósito o primeiro questionário indagou-se sobre a utilização dos recursos das Tecnologias da Informação e da comunicação pelos alunos da turma 303, na Escola Estadual de Ensino Médio Érico Veríssimo de Restinga Sêca. O outro questionário buscou evidências a cerca da utilização das ferramentas Twine e Storybird na produção de Histórias interativas sobre as temáticas históricas de O Cangaço e Guerra de Canudos.

Os dados apresentados a seguir são resultados dos questionários aplicados com os alunos da turma 303, os quais possibilitam a análise, contextualização e tabulação de dados que por ora são aferidos. A figura 4 - Questão 1 (Você acredita que o uso do Laboratório de Informática poderá colaborar com o processo de construção da aprendizagem?) mostra que, dentre os vinte e seis alunos participantes na pesquisa, vinte acreditam que o uso do Labin pode colaborar com os processos de construção da aprendizagem que são conduzidos na escola, quatro acreditam que em parte e dois alunos pensam que o uso desse ambiente não traz nenhum benefício. Essa evidência comprova a necessidade de mudanças metodológicas no processo de condução do ensino e aprendizagem. A realidade apontada confirma que, no entendimento dos educandos, o computador como tecnologia educacional deve propiciar a interação do aluno com o conhecimento através da mediação do professor, este sendo fator determinante no processo de ensino-aprendizagem. Isso é confirmado pela Figura 4 Questão 2 (Você considera que seus professores estão sendo capazes de se apropriar do uso das tecnologias, para conduzir de forma mais atrativa as situações de construção da aprendizagem?), onde a grande maioria respondeu não para a mesma, legitimando a necessidade do constante fomento da apropriação e uso das tecnologias, pelos professores, como ferramentas motivadoras nos processos de construção da aprendizagem.

A Questão Q3 perguntava se os alunos já tinham conhecimento das ferramentas Twine e StoryBird. Todos responderam que não. O resultado evidenciado vai ao encontro do estudo apresentado pela Organização Fundação Telefônica (2014), que buscou entender o comportamento da juventude na era digital. Segundo os resultados da pesquisa, os jovens estão conectados a todo o momento, mas produzem pouco conteúdo. A Figura 5

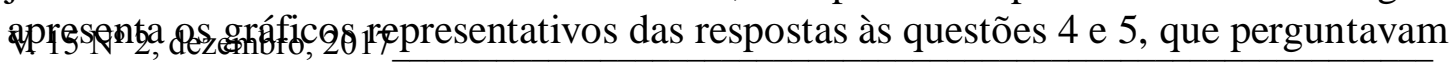


como o aluno considerava a lógica da ferramenta Twine (Questão 4) e StoryBird (Questão 5). Justificamos essa percepção dos alunos em função de que o StoryBird possibilita a ilustração e criação de jogos com cenários que estimulam a criatividade e a imaginação, por meio de imagens já estabelecidas e não há opção de envio de imagens escolhidas pelos autores. Nessa perspectiva, inicialmente os alunos tiveram certa dificuldade em escolher as ilustrações para a criação do jogo de histórias interativas, como já relatado. Além disso, a percepção da programação através de mapas de navegação do Twine tornavam mais fácil para os alunos perceberem as ações que eles estavam desenvolvendo.

Figura 4: Resultados obtidos através de questionários aos alunos (Q1 e Q2)

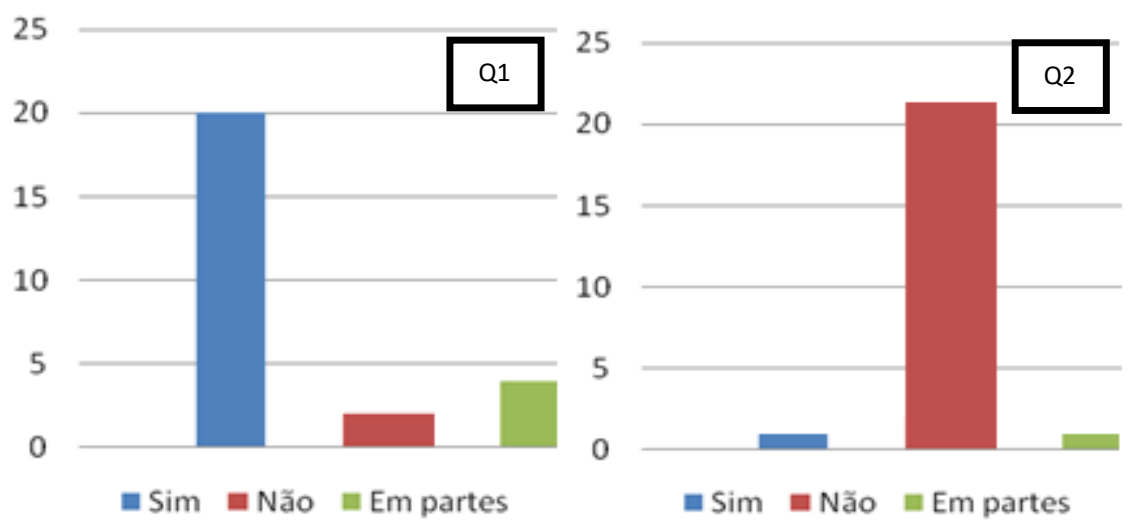

Figura 5: Resultados obtidos através de questionários aos alunos (Q4 e Q5)
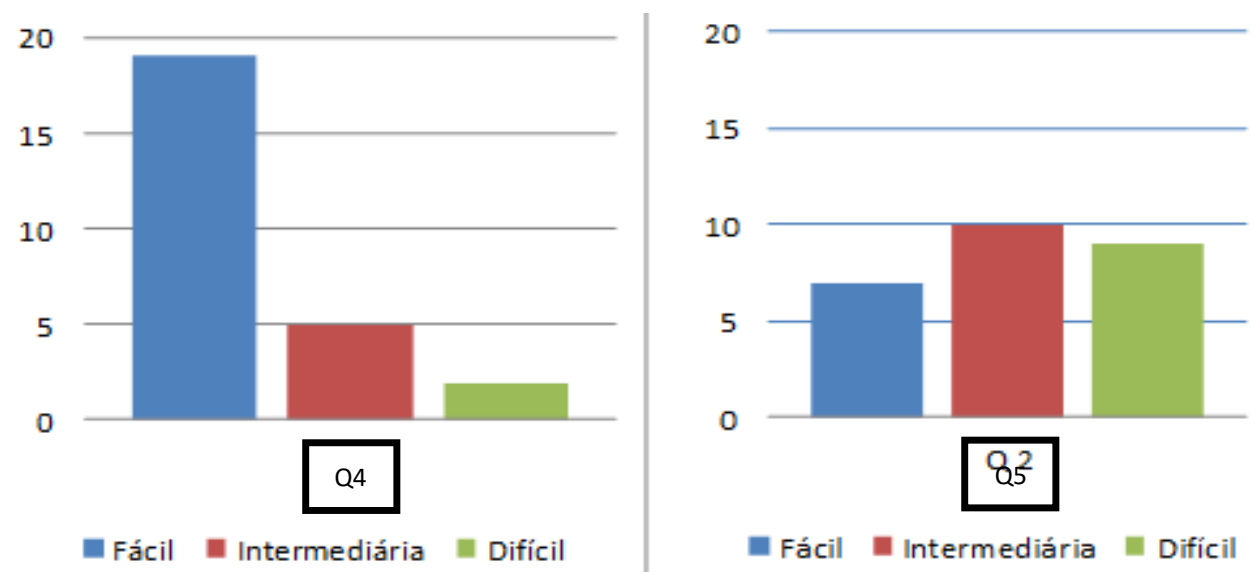

Existem certas questões que sempre estão presentes nas discussões que tratam sobre as metodologias para o ensino de História: "Por que ensinar História?" e "Como ensinar História?", em muitos momentos, esbarra em respostas que consideram essencial a utilização de técnicas que sejam capazes de estimular grandes recuos nos tempos e nada melhor do que a utilização das TICs para o êxito nessa questão. A produção de um jogo de Histórias interativas apresentou aspectos que tornaram as temáticas vivas e proporcionaram situações de reflexões sobre tempo e a relatividade cultural das periodizações. O cerne principal das criações fez uso de uma das principais ferramentas da História, o texto, as palavras e as ideias. Nesse sentido, um grande desafio foi fazer florescer a interatividade, ou seja, o contexto histórico dos períodos de "O Cangaço" e "Guerra de Canudos" precisou ficar vivo e ganhar movimento, por meio da relação dos alunos com as ferramentas utilizadas. Diante disso, percebeu-se nos questionamentos e indagações dos alunos o surgimento do "espírito investigativo" e a curiosidade sobre 
sua própria realidade. Outra atuação de fundamental importância para esse resultado diz respeito à postura do professor que deve fomentar o diálogo constante, a fim de contribuir com o processo de assimilação do conhecimento e uso de novas metodologias.

Dentro dessa perspectiva, as questões Q6 e Q7 perguntavam se a participação do aluno, por meio da produção de um jogo de história interativa utilizando a ferramenta Twine e StoryBird, respectivamente, estimulavam a sua fantasia e curiosidade. Os participantes responderam Sim em sua totalidade para a Q6 e o resultado para a Q7 encontra-se na figura 6. Este resultado apresenta um aspecto positivo, visto que os alunos participantes, quase que em sua totalidade, concordam com subjetividades essenciais para $o$ entendimento da História já acontecida e dos reflexos dessa na sociedade contemporânea. $\mathrm{O}$ resultado apresentado legitima o fomento de um processo educativo que valoriza uma postura ativa e plural, na qual os estudantes agiram como os protagonistas do entendimento dos recortes históricos numa abordagem mais profunda, abandonando o caráter enciclopédico que configura algumas situações no processo de ensino e aprendizagem.

Figura 6: Resultados obtidos através de questionários aos alunos (Q7, Q8 e Q9)
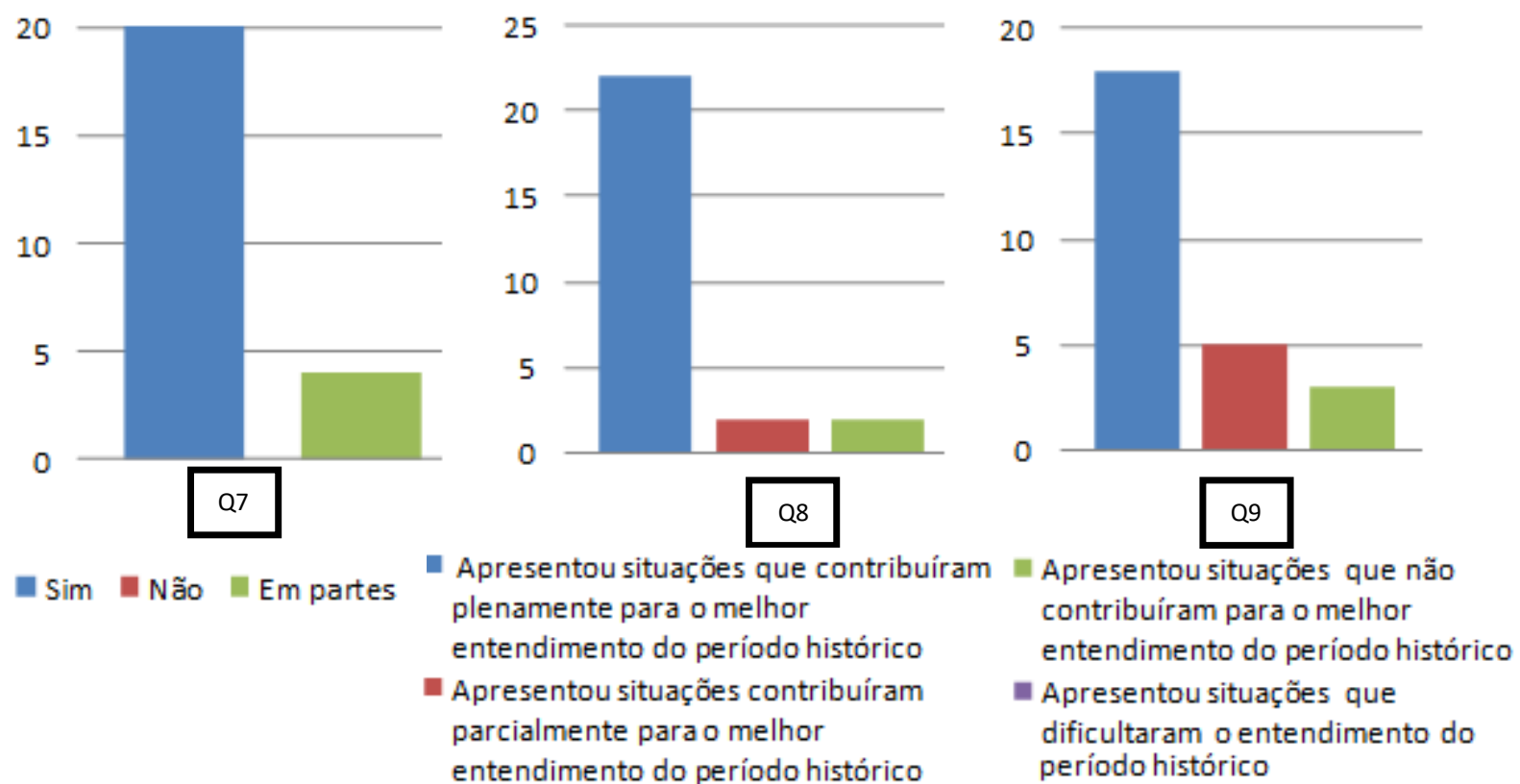

Por fim, foi perguntado nas questões Q8 e Q9 qual eram as conclusões dos alunos sobre as discussões e atividades feitas a partir do jogo de histórias interativas com as ferramentas Twine e StoryBird, respectivamente. Em acordo com dados obtidos, um número significativo dos participantes considerou que as discussões e atividades apresentaram situações que contribuíram plenamente para o melhor entendimento dos períodos históricos referidos. Essas respostas permitem afirmar que a participação dos alunos e suas produções resultaram em situações de entretenimento e crescimento pedagógico, já que ficou evidenciada a satisfação dos alunos na participação da pesquisa. Diante disso, Ferrarezi citado por Strapason (2011), confirmam nossa percepção, ao dizer que entre a função lúdica e a função educativa do jogo, a busca pelo equilíbrio é o principal objetivo. Um jogo na escola pode ter caráter educativo se permitir a livre exploração com o professor a aplicação orientada para conteúdos específicos. 


\section{Conclusões}

A realização dessa proposta de estudo legitima os pressupostos defendidos quando se pensa em abordagens de temas de maneira interdisciplinar. Os dados resultantes nesse estudo referentes à participação dos alunos, empolgação e protagonismo na discussão de ações para a inovação de atividades, permitem concluir que os currículos tradicionais que, de fato, são muito fragmentados, devem urgentemente passar a incorporar novos métodos. Essa necessidade proeminente de mudança que, em muitos casos, parece ser complexa, não requer muitas providências. $O$ que necessita-se urgentemente é o fomento das discussões relacionadas aos avanços tecnológicos ligados aos programas de diferentes disciplinas.

Sabe-se que ainda existem algumas dificuldades para a efetivação do uso das tecnologias nos currículos, uma delas diz respeito é que alguns professores foram formados em licenciaturas específicas. Trabalhar de maneira interdisciplinar e tecnológica exige que o docente saiba mais de uma área ou tenha uma integração forte com os professores das demais disciplinas. As pesquisas realizadas para a fundamentação teórica desse estudo revelam indícios de que a busca dessa integração em muitos casos não é desejo desses próprios professores. A proposição para o trabalho de maneira interdisciplinar e, enfocando temas transversais como tecnologia, história e artes, exige que o professor agregue a seu perfil características diferentes daquelas que eram exigidas na formação de professores de licenciaturas específicas, sem comunicação com as demais.

\section{Referências}

EGENFELDT-NIELSEN, S. The Challenges to Diffusion of Educational Computer Games, the European Conference on Games Based Learning, Copenhagen, 2010.

FAZENDA, Ivani Catarina Arantes. Práticas interdisciplinares na escola: Interdisciplinaridade: definição, projeto, pesquisa. São Paulo: Cortez, 2011.

FRANÇA, Cyntia Simioni; SIMON, Cristiano Biazzo, Como conciliar ensino de Historia e novas tecnologias? Dissertação de Mestrado em Historia Social, Universidade Estadual de Londrina, 2005.

MARKLUND, B.B, ALKIND TAYLOR, A.S, Educational Games in Practice: The challenges involved in conducting a game-based curriculum. The Electronic Journal of e-Learning, V. 14, n. 2, 2016.

MOURA, Mary Jones Ferreira de. O Ensino de História e as Novas Tecnologias: da reflexão à ação pedagógica. In: Simpósio Nacional de História, 25, 2009, Fortaleza 78 CE. Fortaleza: Editora da UFC, 2009.

OLIVEIRA, O. L. Criando e Recriando Histórias. SBIE 2009, v.13, p. 231-230. Campo Limpo Paulista, 2009

SCHOLZE, Lia; RÖSING, Tânia M. K. A escrita e a leitura: fulgurações que iluminam. In: (Orgs.). Teorias e práticas de letramento. Brasília, DF: INEP/UPF, 2007.

SILVEIRA, J. A. Ensino de história: na busca de novas atuações, abordagens e perspectivas. História \& Ensino, Londrina, v. 18, n. 2, p. 203-232, 2012.

STRAPASON, Lísie Pippi Reis. O uso de jogos como estratégia de ensino e aprendizagem da matemática no $1^{\circ}$ ano do Ensino Médio. Dissertação de Mestrado

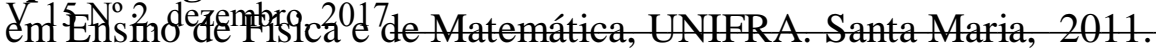

